Vietnam Academy of Science and Technology
Vietnam Journal of Earth Sciences
(VAST)

\title{
New discovery of prehistoric archaeological remnants in volcanic caves in KrongNo, Dak Nong Province
}

\author{
La The Phuc ${ }^{*}$, Nguyen Khac Suㄹ, Vu Tien Duc ${ }^{3}$, Luong Thi Tuat ${ }^{1}$, Phan Thanh Toan², \\ Nguyen Thanh Tung ${ }^{4}$, Nguyen Trung Minh ${ }^{1}$ \\ ${ }^{1}$ Vietnam National Museum of Nature, Vietnam Academy of Science and Technology \\ ${ }^{2}$ Institute of Archaeology, Vietnam Academy of Social Science \\ ${ }^{3}$ Institute of Social Sciences of Central Highlands, Vietnam Academy of Social Science \\ ${ }^{4}$ Phu Gia Phat Company
}

Received 24 January 2017. Accepted 21 February 2017

\begin{abstract}
The Krongno Volcanic Geopark in Dak Nong province with a unique and largest volcanic cave system in SE Asia discovered in 2007 occupies an area about 2,000 $\mathrm{km}^{2}$ in the Krong No, Cu Jut and Dak Mil districts and several neighboring communes in the Dak Song and Dak Glong districts. In 2016, Vietnamese archaeologists discovered a number of archaeological sites in hilly, farmland and riverine areas in the Krong-No Volcanic Geopark; however, none had been found in the volcanic caves. During the late December 2016 - early January 2017 field trip, a survey team led by Vietnam National Museum of Nature, VAST, discovered a series of archaeological sites and relics with a relatively high density in volcanic caves in the Krongno Volcanic Geopark. The discovered archaeological remnants include (1) stone materials and tools such as dish-shaped tools, short axes, blade-ground short axes, oval axes and blade-ground oval axes; flake tools, stone flakes, stone slabs; anvils, graters, pestles, etc., hand-fitting sharp quartzite stones and pieces of loess; (2) pottery, containing various ceramic tools with different thicknesses, mostly fired at low temperature, crumbly, made of fine sandy loam, hand-kneaded, simple forms, mainly pots and containers having relatively sharp sculptings of varied patterns on the pottery shards such as dot-dash, dotted line, dashed line, twisted rope, etc.; (3) animal and teeth bones, including fragments of animal bone, or bones of prehistoric human (?). The bones are mostly decayed and fragile when dry; the hollow portions of bones are filled with porous clay slurry. In addition to the bone fragments, there are cheek teeth of animals some are fossilized. Preliminary determination suggested the teeth are of herbivores. Most of the archaeological artifacts were found in caves with flat floors, having mouths facing east, southeast or south heading to relatively wide areas to absorb the light, close to water sources and convenient to commute. These are the first prehistoric archaeological findings in volcanic caves in Vietnam, which will be studied in more detail by Vietnam National Museum of Nature, VAST, and other authorized agencies to highlight a new type of settlement, a new adaptive trend of prehistoric dwellers in the Central Highlands and to open a new archaeological study in the volcanic caves in Vietnam and Southeast Asia.
\end{abstract}

(C2017 Vietnam Academy of Science and Technology

\section{Introduction}

Krong No Volcanic Geopark (KVG)

*Corresponding author, Email: laphuc@gmail.com contains not only important geological values but it also bears cultural, ecological and archaeological meaning, that meets some of the UNESCO criteria of an aspiring global geopark (UNESCO, 2009). The nominated 
KVG covers an area of about 2,000 $\mathrm{km} 2$ in Krong No, Cu Jut, Dak Mil districts and several neighboring communes in Dak Song and Dak Glong districts (Figure 1).

While implementing the science and technology project on "Investigation and assessment of geological heritage and establishment of Krong No Geopark, Dak Nong province", several questions relative to the cultural heritage were raised to what were the significant archaeological values in the KVG? How did prehistoric people live on and adapt to changes in the landscape and ecological environment throughout thousands of years? How did they exploit the local natural resources to meet their needs? To answer these questions, in January 2017, a survey team including geologists, culturologist, and archaeologists, led by Vietnam National Museum of Nature, VAST, re-examined the old relics, started the new survey and has discovered a number of archaeological sites in the volcanic caves in the Krong No district. The survey has shown some surprising results.

The archaeological records show that before 2017 archaeologists had discovered more than 30 archaeological sites in Dak Nong province (Nguyen Khac Su, 2007; Vu Tien Duc, 2015), none of this was in the volcanic cave. Archaeological remnants were collected at 12 sites in KVG, including Trung Son, Thac Lao, Suoi Tre, Thon Sau, Thon Bay and Thon Tam (Cu Jut district), Canh Nam, Nam Xuan (Krong No district), Truong Xuan, Dak Ton (Dak Song district), Dak R'la, Dak Lao (Dak Mil district). Among these, the archaeological site at Thon Tam, Dak Wil commune, $\mathrm{Cu}$ Jut district, was excavated twice in 2006 and 2013. The initial research results of these sites indicated that the remnants belong to the Neolithic Age and Early Metal Age, about 6,000 to 3,000 years ago (Le Hai Dang et al., 2013; Nguyen Gia Doi, Le Hai Dang et al., 2006; Nguyen Khac Su, 2004, 2007; Truong Quang Quang et al., 2011; Vu Tien Duc, 2015).

\section{Archaeological objects in volcanic caves in KVG}

\subsection{Geology of volcanic cave area}

The geological formations in the volcanic cave area are relatively simple, comprising only of La Nga, Xuan Loc and unconsolidated Quaternary formations (Figure 2).

La Nga formation (J2ln) is widely distributed in the west of cave area (Figure 2) and consisted mainly of terrigenous sediments which are divided into three sections. Section 1: weathered and cracked gray siltstone turned yellowish gray color; blackish gray claystone with the shiny surface with intercalation of thin layers of yellow sandstone; darkish gray sandy siltstone; the thickness being about 250 $300 \mathrm{~m}$. Section 2: black siltstone thinly layered, with idiomorphic pyrites scattered on the surface along with clayish shale fragments, and thin layers of sandstone containing white mica flakes; the estimated thickness about $100 \mathrm{~m}$. Section 3: gray, light gray, yellowish gray medium-to-fine sandstone alternating with gray, yellowish gray sandy siltstone, siltstone and thin layers of claystone; the thickness being about 350-400 m (Nguyen Duc Thang, 1989).

Xuan Loc formation $\left(\beta / \mathrm{Q}_{1}{ }^{2} \mathrm{Xl}\right)$ is widely distributed in the central part shown in Figure 1 , with basaltic rocks being the main component which is divided into three sections. Section 1: The brownish gray-to-black volcanic ash, sometimes tuff interbedded with layers of gray porous basalt; the thickness of about $35 \mathrm{~m}$. Section 2: basaltic lavas including olivine basalt, darkish gray dolerite, plagiobasalt, having mostly massive structure; the thickness of about $45-50 \mathrm{~m}$. Section 3: consisting of fissured lava flows along with explosive eruptive products with black, grayish green olivine basalts being the main rock type, some subordinate amount of volcanic bomb and breccia. The basalts are massive and a minor amount of porous type; the thickness is about $45-51 \mathrm{~m}$ (Nguyen Duc Thang, 1989). 
Vietnam Journal of Earth Sciences, 39(2), 97-108

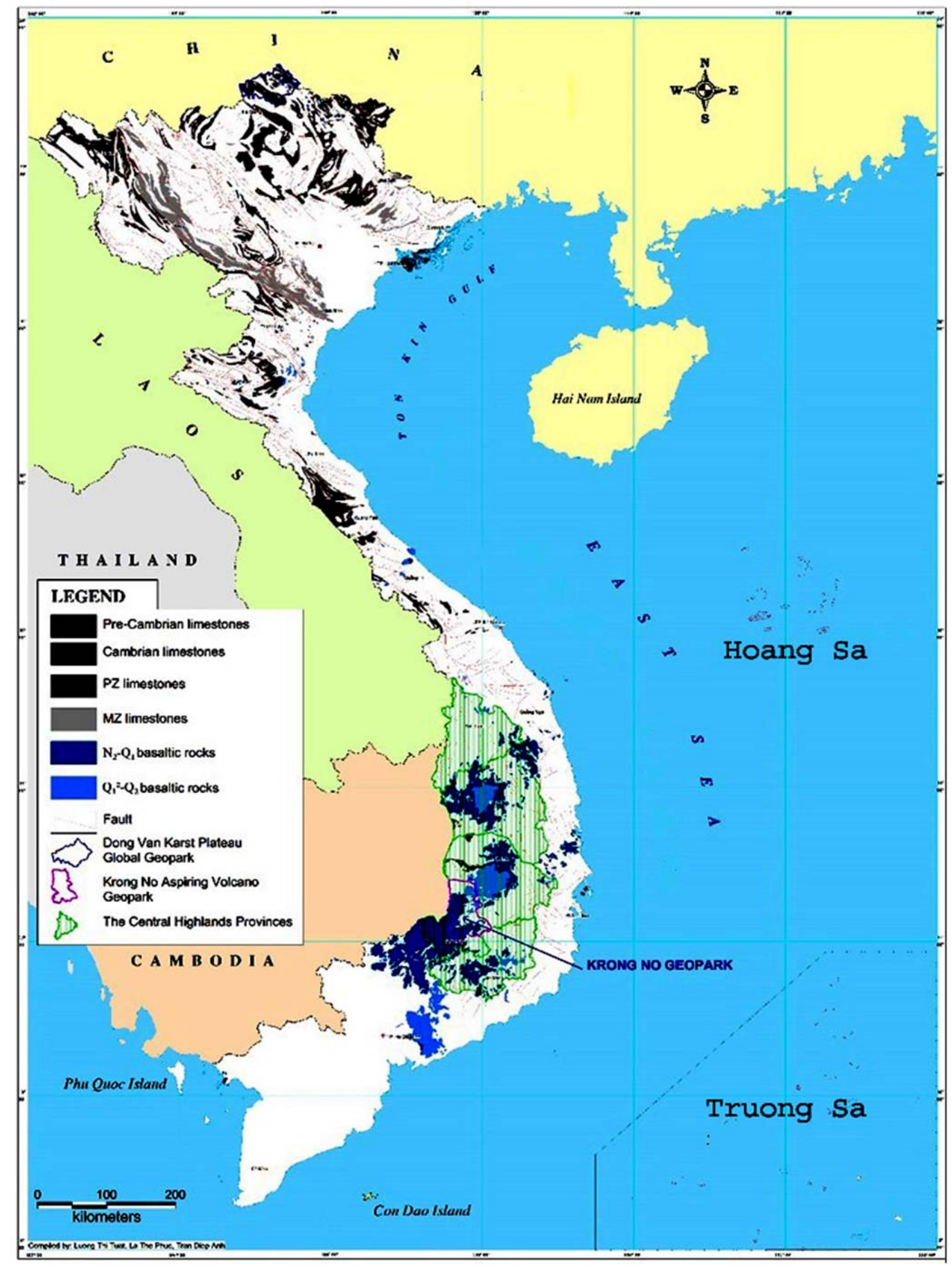

Figure 1. Distribution map of Krongno volcanic geopark in related geological formations in Vietnam 


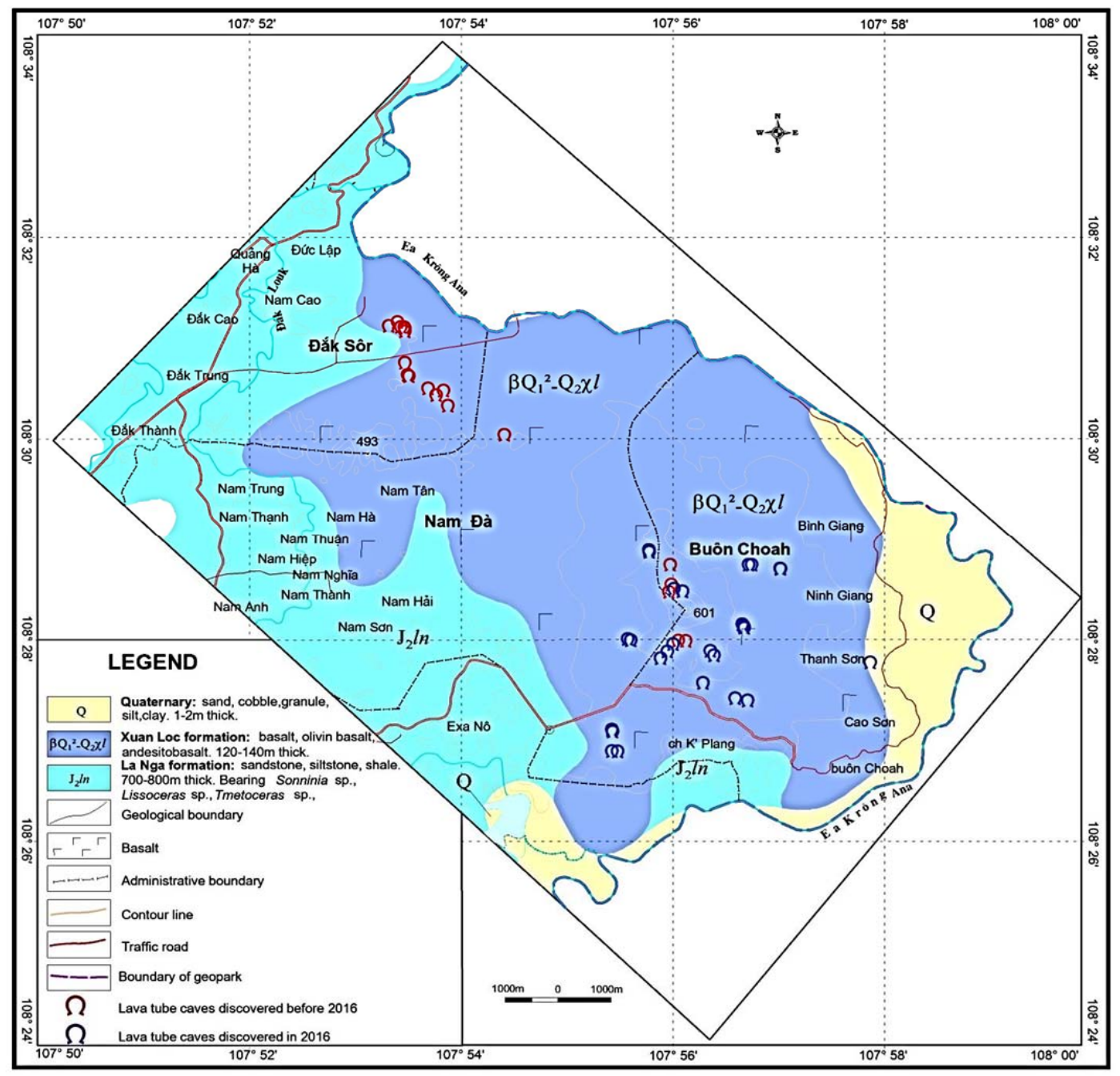

Figure 2. Distribution map of volcanic caves in Krong No

Undivided unconsolidated Quaternary formations $(\mathrm{Q})$ are widely distributed in the east of the cave area (Figure 2), comprising sandy clay, patchy-colored silty clay and laterite, occurred as unconsolidated accumulations in the lower session, forming the firstorder terrace of the Srepok River, 3-6 m high; the total thickness is about 5-6 m (Nguyen Duc Thang, 1989).

Mineral resources in the study area are mainly puzzolanas a weathered product from
Xuan Loc basaltic formation in the Buon Choah commune, Krong No district. Besides, basaltic construction material and brick-made clay are found along the Srepok River valley (Nguyen Duc Thang, 1989).

\subsection{Geological characteristics of the ar- chaeological site-housing caves}

Cave systems discovered in the area are related to the Xuan Loc basalt formation (Figure 2). So far Chu B'Luk volcano in the Buon 
Choah commune, Krong No district $(601 \mathrm{~m}$ high relative to sea level, the crater is $\sim 63 \mathrm{~m}$ deep) is the only visible volcano in the area. Caves are found scattered around this volcanic area. Most of the current cave mouths are secondary, formed following cave ceilings' collapse; as a result, they are usually domeshaped, and basaltic rock boulders are commonly seen nearby. Some cave mouths are primary, formed following the emission of volcanic gas and the cooling of eruptive basaltic lavas. These mouths are usually circular, steep to great depth (depth of C7 cave $>10 \mathrm{~m}$, "Python" cave $\sim 25 \mathrm{~m}, \mathrm{P} 9$ cave $\sim 23 \mathrm{~m}$ ). Currently, only archaeological sites related to cave with secondary mouths have been discovered; especially, in caves with flat floors near wide, easily accessible, well-light mouths, and close to water sources. In contrast, archaeological artifacts were not yet found in caves with narrow mouths, poorly light and stuffy.

\subsection{The archaeological discovery in the Krong No Volcanic Geopark}

Thon Tam site: The archaeological site in Thon Tam (Dak Will commune, Chu Jut district) was excavated in 2006 with an area of $52 \mathrm{~m}^{2}$ and in 2013 with an area of $37.5 \mathrm{~m}^{2}$. The site is at altitude $382 \mathrm{~m}$ relative to the sea level and coordinates of $12042^{\prime} 31.3^{\prime \prime} \mathrm{N}$ and 107048'25.9''E. The two excavation sites provide the same results. The cultural relics include stone tools, semi-finished tools, stone flakes, stone materials and pottery found in a red basaltic weathering bed with a thickness of $50 \mathrm{~cm}$. However, no traces of residential architecture, animal bones, charcoal ash were found. The discovery of the remnants suggests that Thon Tam was a stone ax 'factory', dated to the Middle Neolithic (about 5,000 years ago) (Le Hai Dang et al., 2013; Nguyen Gia Doi, Le Hai Dang et al., 2006; Vu Tien Duc, 2015).

The survey around the excavation site in Thon Tam (Dak Will, Chu Jut district) at the altitude of $335 \mathrm{~m}$ has found other 15 hills (now are black pepper plantations or industrial plants) surrounded by water pools. On the surface of these hills found were semi-finished stone axes, stone flakes, and stone materials. The discovery of oval axes, short axes, discshaped scrapers with one or both knapped sides and polished edge in this area bearing Early Neolithic making techniques of the Hoa Binh Culture, well-known in Vietnam and Southeast Asia, suggesting that the area is a concentration of remnants of prehistoric settlers in the Central Highlands.

The survey of remnants in volcanic caves: C1 cave (Figure 3, Survey point: KVG107, GPS symbol: 083).

The cave is about $300 \mathrm{~m}$ from a nearby pathway, easily accessible. Its mouth is nearly isosceles triangular (Figure 3), facing the east at $90^{\circ}$, the width of the base about $3.5-4 \mathrm{~m}$, the ceiling about $3 \mathrm{~m}$ high, and $>100 \mathrm{~m}$ long. The mouth of $\mathrm{Cl}$ cave was formed by thin and weak ceiling collapse. At the center of the floor closer to the mouth there is a narrow basaltic ridge with rough surface due to solid lava 'stalagmites', all looks like a large crocodile, heading to the cave mouth (Figure 4). Pieces of pottery, potsherds with dotted line pattern, red pottery broken pieces, made by fine sandy clay, low temperature fired, were collected on the floor. In addition, angular quartz fragments, 2 to $4 \mathrm{~cm}$ size were found in the cave. Whether these fragments were quartz tool-making wastes of prehistoric people or of shooting projectiles of homemade catapults of the local people remain unanswered. Several pieces of ocher-stained limb bones were also recovered in the cave, possibly human bones (?).

From the mouth of $\mathrm{C} 1$ cave to $100^{\circ}$ eastward is part of the same cave having ceiling collapse forming a double-mouth cave. There is a sunroof near the eastern mouth, with a diameter of about $1.7 \mathrm{~m}$. This part of the cave is about 17-20 $\mathrm{m}$ long expanding in the sublatitudinal direction. Especially, a tree-shaped mold, more than $5 \mathrm{~m}$ long and about $10 \mathrm{~cm}$ in diameter, is seen on the south wall. 


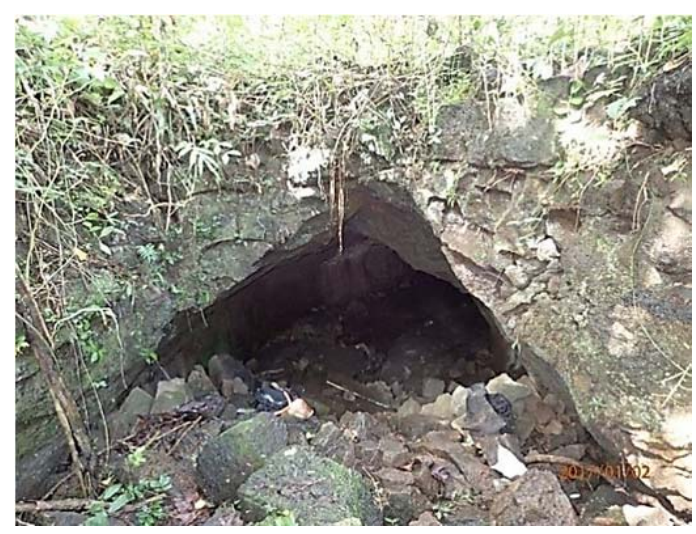

Figure 3. Mouth of $\mathrm{C} 1$ cave

At the foot of the northern flank of C1-1 cave, a black soil trench was discovered containing many potsherds, pottery parts of 2-3 $\mathrm{mm}$ thick, some incised with dash patterns. Found also were a few shells of mountain snails, including Cyclophorus sp.

- C3 cave (Survey point: KVG108, GPS symbol: C3): $\mathrm{C} 3$ cave is about $1 \mathrm{~km}$ westnorthwest from $\mathrm{C} 1$ cave. The cave is $594.4 \mathrm{~m}$ long (La The Phuc et al., 2015) having mouth facing east at $110^{\circ}$. The mouth was collapsed, currently is about $4.5-5 \mathrm{~m}$ below the surrounding relief, $20 \mathrm{~m}$ wide, $15 \mathrm{~m}$ high, with basalts falling following the ceiling collapse piling up in front. The thickness of current ceiling cover is about $3-5 \mathrm{~m}$. A tree-shaped mold is seen on the left wall of the mouth having a diameter of about $40 \mathrm{~cm}$. Rock boulders up to several cubic meters are seen scatter on the floor. C3 cave at its current stage is not suitable for settlement, however, if it was a place of prehistoric humans, any remnants left must be buried under the falling rocks. No archaeological relics have been found in the cave.

- C4 cave (Survey point: KVG109, GPS symbol: C4): C4 cave is $251 \mathrm{~m}$ long, about $300-400 \mathrm{~m}$ from $\mathrm{C} 3$ cave southeastward ( $\mathrm{La}$ The Phuc et al., 2015). The mouth is in a 5-8 $\mathrm{m}$ deep depression, resulted from a ceiling collapse, half-round-shaped, facing south at

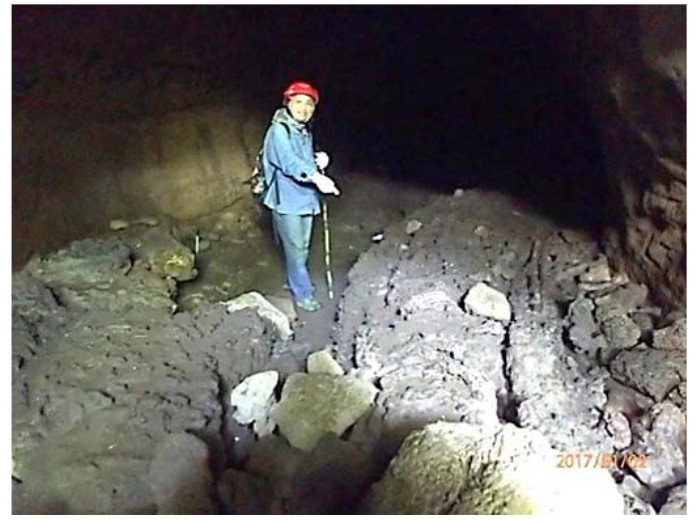

Figure 4. C1 floor

$190^{\circ}$. The ceiling height $4.5-5 \mathrm{~m}$ high and the cave is $12-15 \mathrm{~m}$ wide. The floor is relatively flat, lower towards the mouth, covered with moist soil and basalt fragments with sizes of $10-40 \mathrm{~cm}$. The floor is gradually higher as the cave becomes deeper, exposing solid basaltic bedrock (Figure 5). About $40 \mathrm{~m}$ from the mouth the cave turns left and extends deep inside. A large basaltic boulder, about $1.5 \mathrm{~m}^{3}$, lies near the mouth also as a result of the ceiling collapse. Several archaeological artifacts were discovered near the mouth, including pebble materials, axes, stone flakes, anvils made from riverine pebbles, a piece of opal chalcedony; animal teeth, loess with the trace of rodent teeth. Also found are crude potteries, small pottery pieces of 2-3 $\mathrm{mm}$ showing sculpting decoration similar to those observed on ceramics of the Neolithic Age in this area dated at 4,000-5,000 years ago (Figures 5, 6, $7,8,9,10,11)$.

- Additional survey point in the area of C4-1(Survey point: KVG109/1): Southsoutheastward from $\mathrm{C} 4$ cave, across a lowland because of the ceiling collapse, there are two short cave branches lying parallel each other. Each cave is $100 \mathrm{~m}$ long with two mouths at both ends (due to ceiling collapse). Two northwestern mouths face $330^{\circ} \mathrm{NW}$, towards the C4's mouth. These two branch caves, hav- 
ing similar sizes, were possibly separated from the main $\mathrm{C} 4$ cave. The sectional area of each branch is elliptical, about $12 \mathrm{~m}$ high and 15-20 m wide. A pile of basaltic rocks formed by ceiling collapse is seen near the southern mouth of the eastern cave. The wall in the northern mouth of the eastern cave is composed of porous basalt with large vesicles, coated with a thin layer of volcanic glass. Fragments of broken riverine pebbles and stones with hitting cracks (material stone) of prehistoric humans were found on the floor in the western branch cave.

- C6 cave (Survey point: KVG117, GPS symbol: 091): C6 cave is $180.3 \mathrm{~m}$ long, about $200 \mathrm{~m}$ from $\mathrm{C} 4$ cave to the east, with the mouth facing southeast at $140^{\circ}$ (La The Phuc et al., 2015). The cave spreads in the southeast - northwest direction from the mouth. A light well, about $2 \mathrm{~m}$ in diameter, is located at the

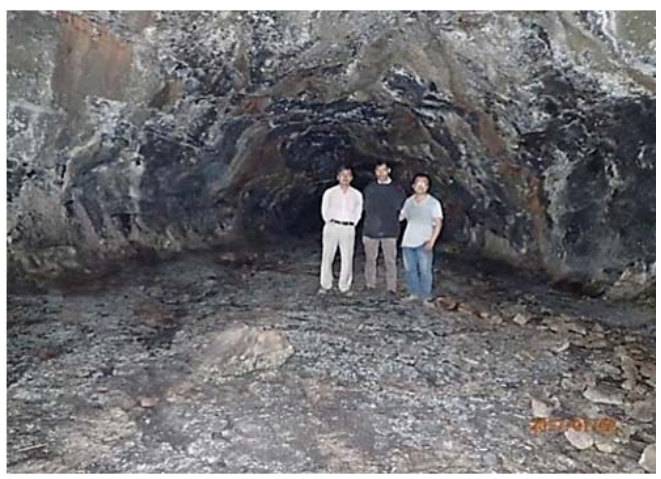

Figure 5. Mouth of C4 cave

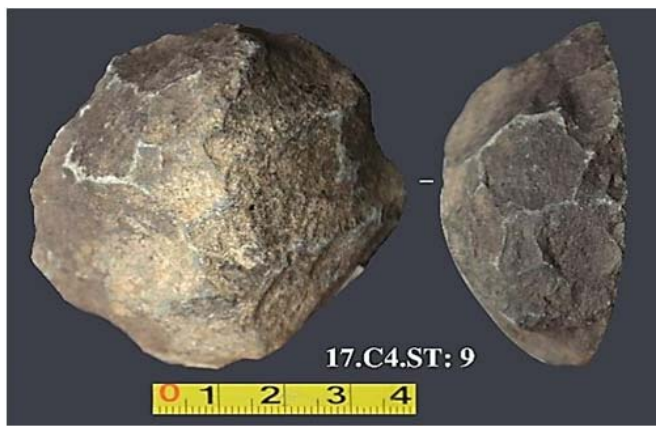

Figure 7. Disc-shaped tool, C4 cave end of the northwestern side. The ceiling coating is fairly solid, $5-8 \mathrm{~m}$ thick above the mouth and gradually becoming thinner inside. From the light well, a branch expands to the northeast, then makes an elbow-sharp turn southward to join the major cave branch. The floor of the minor branch is higher than the main branch and is relatively flat. The place is good for living for privacy and air circulation thank to the light well at the end of the cave. The floor of the major branch is relatively smooth, except for some basaltic rocks scattered on the floor. In general, the C6 cave is favorable for the residence of prehistoric people. Many archaeological artifacts were discovered in the cave such as semi-finished stone axes, basaltic stone flakes, loess, gravels, and thick potsherds of $1.5-2 \mathrm{~mm}$ with plain surfaces or having twisted rope pattern (Figures 12, 13, 14).

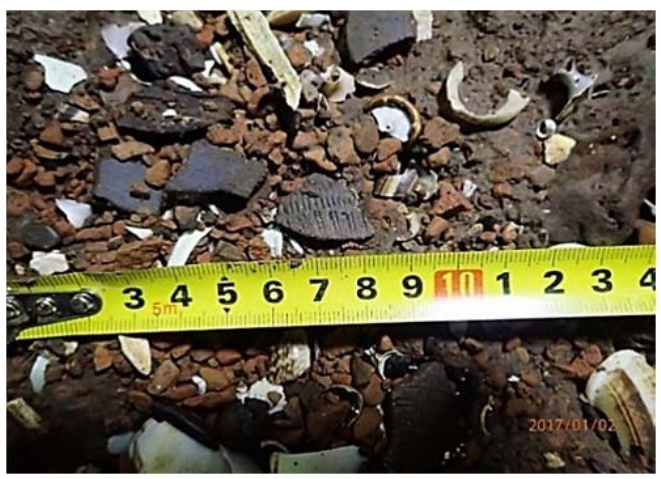

Figure 6. Stones and Potteries at $\mathrm{C} 4$ cave

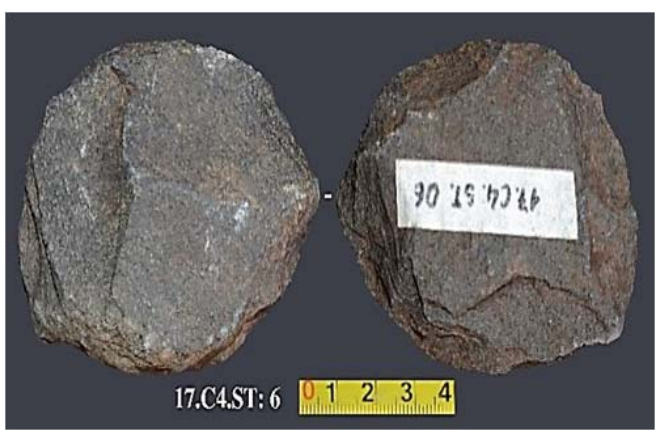

Figure 8. Disc-shaped tool, C4 cave 


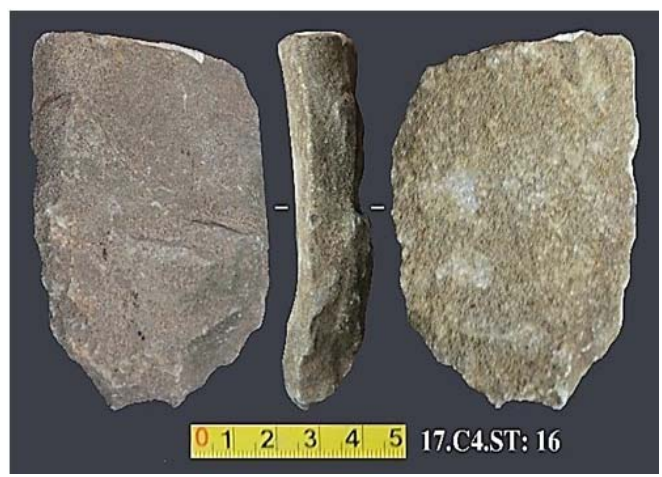

Figure 9. Short axe, C4 cave

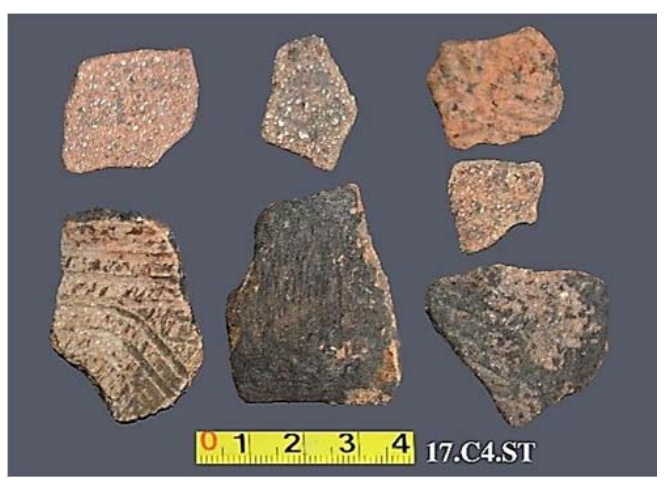

Figure 11. Potteries, C4 cave

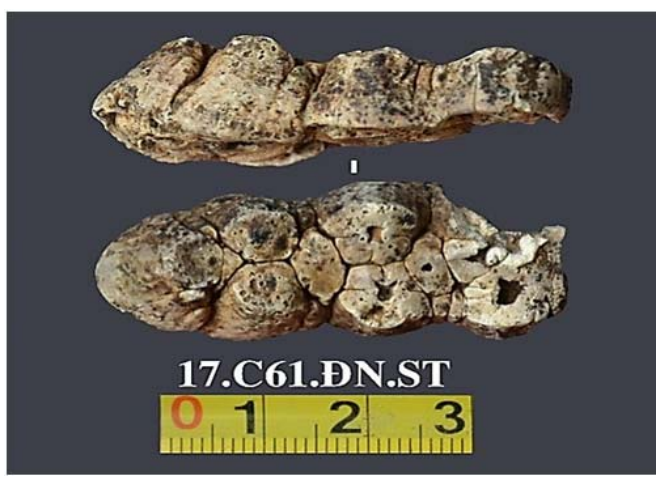

Figure 13. Fossil of pig teeth, C6 cave

- C6' cave (Survey point: KVG118, GPS symbol: 092): C6' cave is approximately $200-$ $300 \mathrm{~m}$ from C6 cave south-southeastward, with a dome-shaped mouth $>10 \mathrm{~m}$ high (Figure 14). C6' cave is ellipse- shaped, about $15 \mathrm{~m}$ wide and $13 \mathrm{~m}$ high. It is possible that C6 and C6' caves were once a unity but

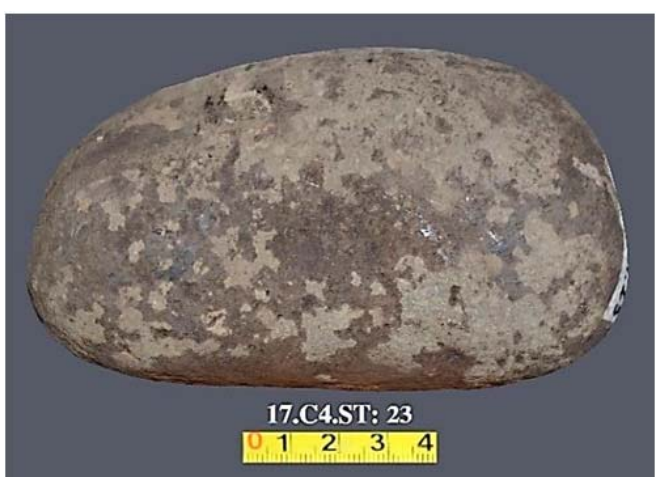

Figure 10. Anvil made from pebble, $\mathrm{C} 4$ cave

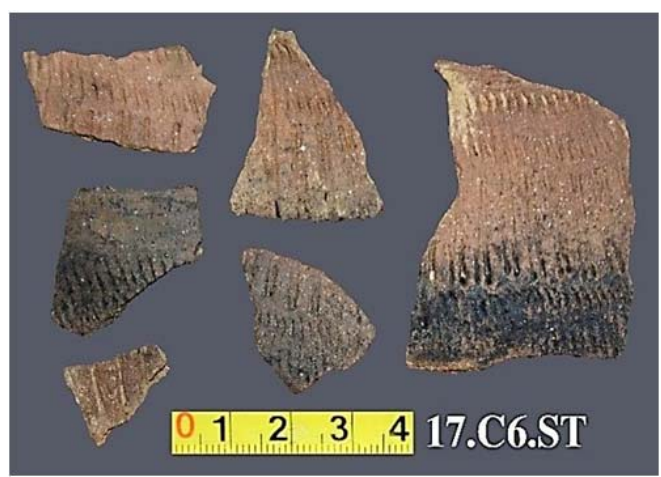

Figure 12. Potteries, C6 cave.

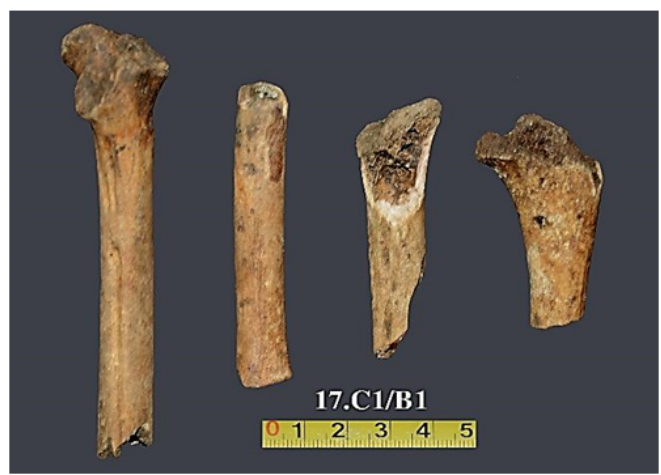

Figure 14. Human limb bones (?), C6 cave

divided following a ceiling collapse. The floor of C6' cave is relatively flat, with basalt rocks protruding on both walls. There are grooves on the wall of C6' cave, suggesting lava flow direction. The alignment of grooves is vertical or twisted, along with gravitationally oriented stalactites observed on the walls, suggesting 
that the lava flows by were twisted, leaned along the cave walls due to gravitational effect during the C6' cave formation process. Inside the cave, nearby the mouth 13 stone artifacts, 27 potsherds and several pieces of animal bones and teeth were discovered. The stone remnants include 3 pieces of material stone derived from riverine pebbles from Srepok River (?); claystone, quartz and clay siltstone slate; 6 pieces of primary and secondary stone flakes, separated from claystone, fine-clay siltstone, with sizes shorter than $7 \mathrm{~cm}$; 4 stone axes with one knapped side, 2 made from basalt, others made from metamorphosed siltstone to quartzite state (Figures $16,17,18,19,21)$. Pottery was made from coarse-grained sandy clay; ceramic coating of some pieces was peeled. The surface was incised with dash patterns or dash- circle-shaped patterns. There are two pieces with bulging mouth, bell-shaped, thick edge; and roundingshaped, without mouth edge; one piece with

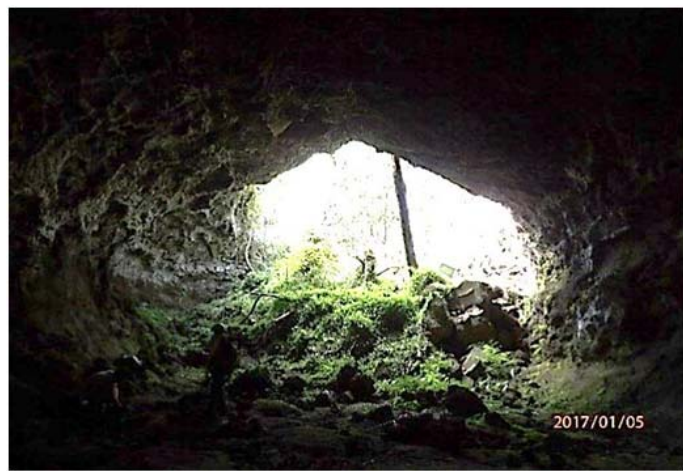

Figure 15. Mouth of C6 cave

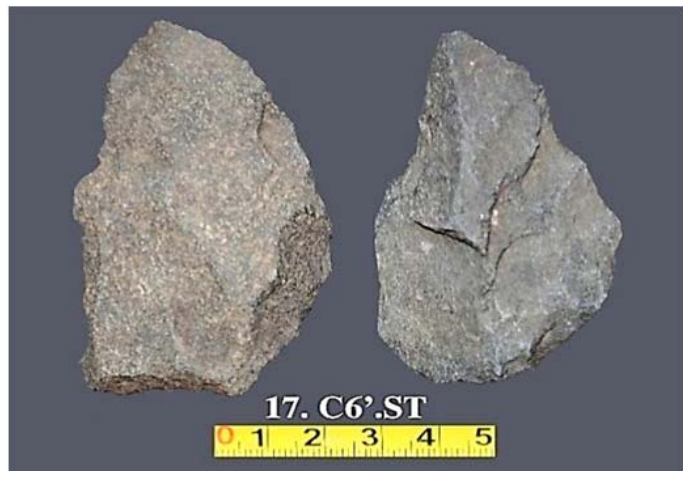

Figure 17. Stone flake, C6 cave mouth decorated with incised dash and circleshaped patterns, having the thickness about 0.4-0.6 cm (Figure 19).

- C6.1 cave (Survey point: KVG120): C6.1 cave is $293 \mathrm{~m}$ long, about $270 \mathrm{~m}$ from C6 cave south-southeastward (La The Phuc et al., 2015). This area is a largely subsided terrain containing 3 cave mouths:

+ Mouth 1: faces north at $10^{\circ}$; two potsherds were found here;

+ Mouth 2: faces east at $100^{\circ}$. Several archaeological artifacts were discovered by local people while exploiting bat droppings at this site.

+ Mouth 3: faces south at $160^{\circ}$. Like mouth 2 , while digging the cave foundation for bat droppings local residents found many archaeological artifacts, including tools such as oval axes, blade-sharpened oval axes, blade-sharpened short axes (Figures 22, 23, 24), stone flakes and potteries similar to those in $\mathrm{C} 4$ cave.

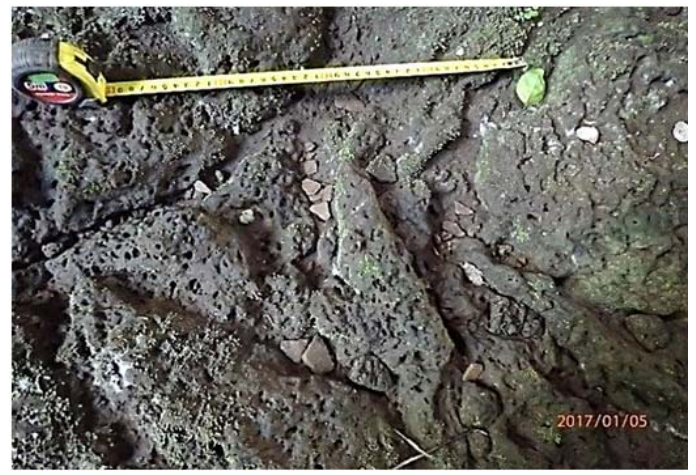

Figure 16. Relics on the floor of $\mathrm{C} 6$ cave

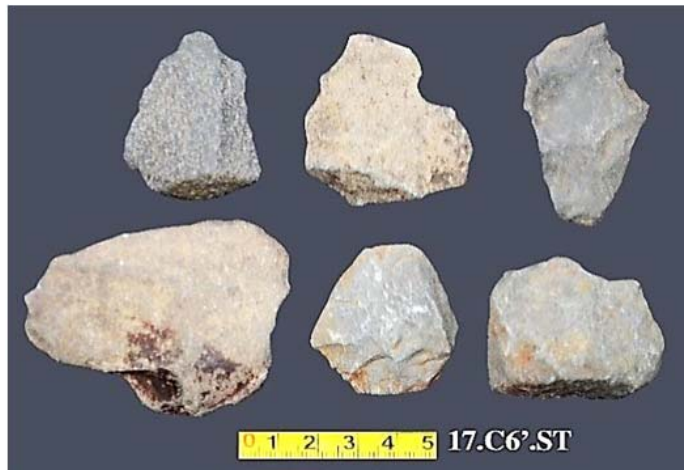

Figure 18. Stone flakes, C6 cave 
La The Phuc, et al./Vietnam Journal of Earth Sciences 39 (2017)

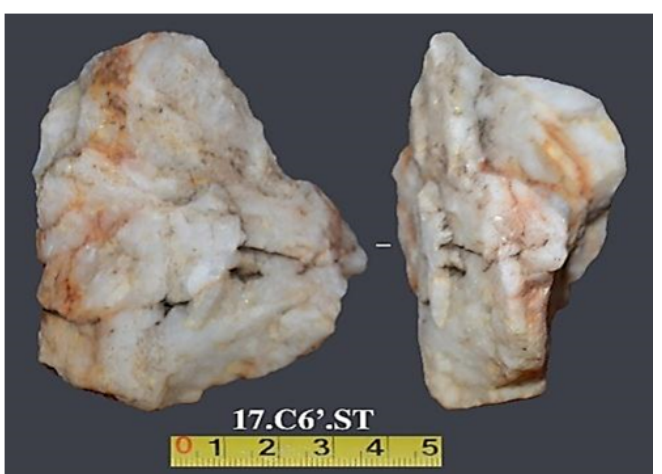

Figure 19. Quartz tool, C6 cave

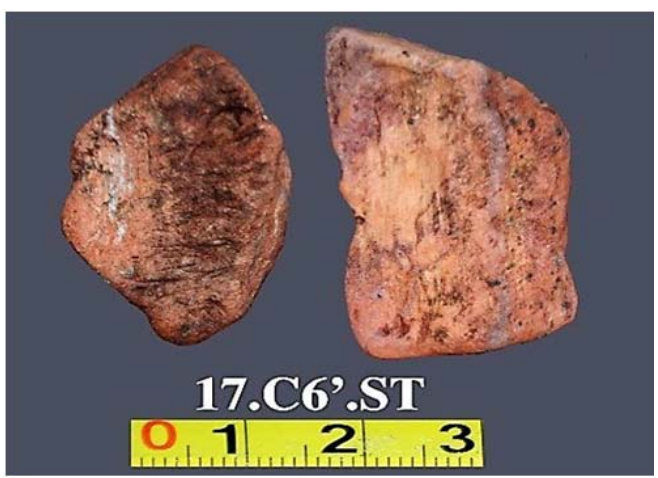

Figure 21. Ocher at C6 cave

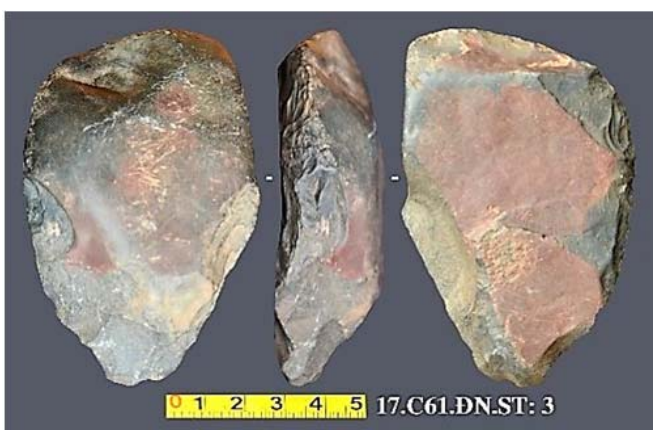

Figure 23. Oval axe with polished edge C6.1 cave

\section{Initial Remarks}

- There are many archaeological sites in the Krong No Volcanic Geopark area, particularly in the volcanic caves. Preliminary surveys from cave $\mathrm{C} 1$ to cave $\mathrm{C} 6.1$, we have found prehistoric archaeological sites containing pieces of evidence of early human settlement and tool making in the volcanic caves.

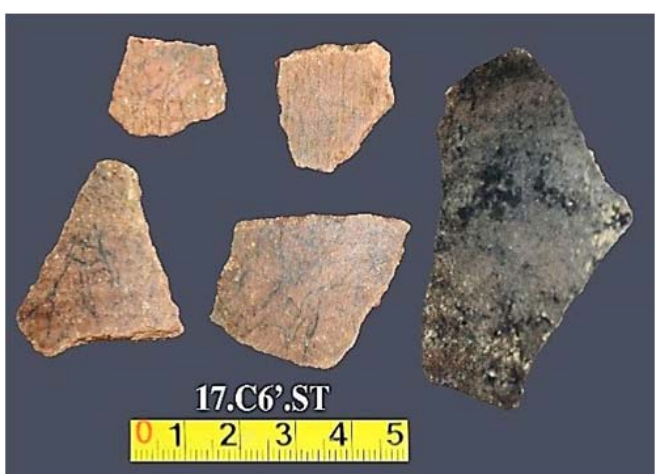

Figure 20. Potteries at $\mathrm{C} 6$ cave

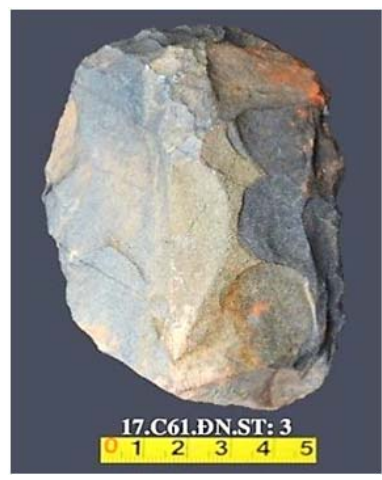

Figure 22. Oval axe at C6.1 cave

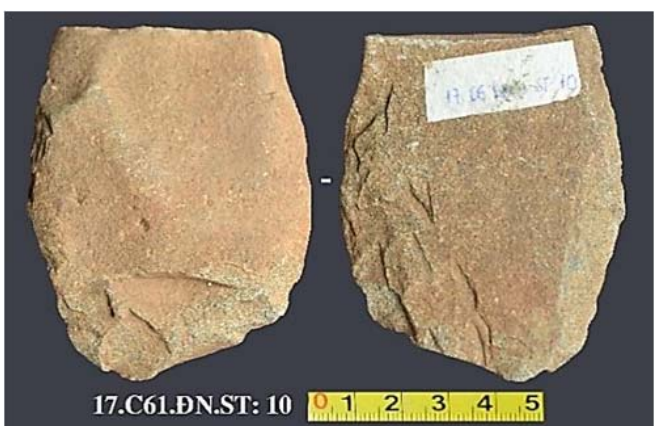

Figure 24. Short axe with polished edge, C6.1 cave

These are the first prehistoric archaeological findings in volcanic caves in Vietnam.

- The volcanic caves in the Krong No volcanic area, in particular, and the Central Highlands, in general, were very meaningful to the prehistoric dwellers, especially when their living techniques were low. The inspected caves in the KVG area are relatively wide, well- 
ventilated, and easy to approach. With smooth floors, proximity to water resources, mouths facing east, southeast or south to receive the light, these caves appeared to meet ideal prerequisites of "cavemen" to settle in. The survey revealed that ancient people did reside in the volcanic caves and take shelter under basaltic roofs where they made their stone tools and potteries with relatively high skill;

- In creating stone tools, they knew how to choose hard and ductile riverine pebbles such as silicic chert, silica-rich shale, quartzite or quartz, etc. They used stone knapping techniques directly on one or two sides to create the tool edges. Sometimes they used chopping techniques to separate stones into flakes for tool making. Beside major knapping techniques, they could also use sophisticated knapping techniques to improve and smoothen blade edges.

With regards to forms, the ancient people were able to make shaped tools, such as oval or sub-rectangular axes, sub-circular tools, stone flakes, stone slabs, anvils, pestles, etc. These tools were common in tribes during the Neolithic Age. By experiment, observation and ethnographic comparison, archaeologists suggested that these tools could be used to cut down trees, clear forests, butcher wild animals, slice herbs, prepare food or work on bamboos or woods into tools and hunting weapons.

Although only a few ceramic remnants have been discovered in the caves, but they indicate being produced with the ingenious techniques. They are potteries, made from fine sandy clay, manually molded, simple forms, mostly pots and containers with a thin ceramic frame, ceramic coating, square-shaped decoration with incised dash or dotted patterns. These are common ceramics in the archaeological remnant in the Late Neolithic and Early Metal Age.

- With tools preserving the techniques of post - Hoa Binh culture and ceramic features, it can be suggested that there may be many generations resided successively in the caves and under rock shelters in the KVG, dated from the Middle Neolithic (6,000-7,000 years ago) to the Metal Age $(2,000-3,000$ years ago), even in the last several centuries. To clarify this prediction, it is necessary to carry out excavations, stratigraphic studies, chemical analyses on the ceramic and rock samples chemical and petrological compositions and ages by spore and pollen tests and radiometric dating.

- This is the first time the residential relics of prehistoric people have been discovered in volcanic caves and under basaltic rock shelters in Vietnam, highlighting a new type of settlement, a new adaptive trend of prehistoric dwellers in the Central Highlands and opening a new archaeological study in the volcanic caves in Vietnam and Southeast Asia.

However, these are only the initial findings, the geologists in Vietnam National Museum of Nature and the archaeologists of the Institute of Archeology should continue to discover new cave remnants, to carry out the excavations and systematic intensive studies on these remnants, contributing to the research on cultural-historical process of inhabitants in Dak Nong and in Central Highlands, in general, adding a great valuable of culturehistory of prehistoric humans in KVG.

\section{Aknowlegements}

The survey team gratefully thank Vietnam National Museum of Nature, VAST, Department of Science and Technology and leaders of Dak Nong for providing the most favorable conditions for the survey team to fulfill the scientific study and achieve the new findings. This report was completed during the implementation of the project "Investigation and assessment of geological heritage and establishment of Krong No Geopark, Dak Nong province".

\section{References}

La The Phuc, Hiroshi Tachihara, Tsutomu Honda, Truong Quang Quy, Luong Thi Tuat, 2015. The geological heritage of unique volcanic cave in Dak 
La The Phuc, et al./Vietnam Journal of Earth Sciences 39 (2017)

Nong has been discovered and established the record. Journal of Geology, Series A, 349, (1-2), 28-38.

Le Hai Dang, et al., 2013. Preliminary results of the second excavation in the Thon Tam archaeological site (Dak Nong), in "New discoveries in archeology in 2013”, 103-105.

Nguyen Gia Doi, Le Hai Dang, et al., 2006. Discovery of archaeological site of stone tool workshop in Thon Tam (Dak Nong). In "New discoveries in archeology in 2006". Social Sciences Publishing House.

Nguyen Duc Thang (Chief Editor), 1989. Geology and Minerals in Ben Khe - Dong Nai map sheet group, on the scale 1:200,000. General Department of Geology and Minerals of Vietnam, Hanoi.

Nguyen Khac Su (Chief Editor), 2004. Prehistoric archaeology in Dak Lak. Social Sciences Publishing House, Hanoi, 260p.
Nguyen Khac Su, 2007. Prehistoric archaeology in the Central Highlands. Education Publishing House, Hanoi, 138p.

Nguyen Van Tran, Hoang Thu Nguyen, 2011. The discovery of stone axes in Dak Song (Dak Nong). In "New discoveries in archeology in 2009". Social Sciences Publishing House, 96-97.

Truong Quang Quang, et al., 2011. The newly discovered stone hoes in $\mathrm{Cu}$ Jut (Dak Nong). In "New discoveries in archeology in 2010". Social Sciences Publishing House, 97-98.

UNESCO Division of Ecological and Earth Sciences, 2009. Global Geopark Network.

$\mathrm{Vu}$ Tien Duc, 2015. Report of scientific project at Institute of Social Sciences of Central Highlands "Investigation of prehistoric archaeological remains in Dak Wil, Cu Jut, Dak Nong', 67. 